\title{
Effects of Water Treatment Residuals on the Kinetics of Ni(II) Sorption and Desorption in Some Arid Soils
}

\author{
Mohamed N. Almanea ${ }^{1}$, Elsayed A. Elkhatib ${ }^{1 *}$, and Ahmed M. Mahdy ${ }^{1}$
}

\begin{abstract}
The mobility and bioavailability of nickel (Ni) is strongly dependent on the mechanisms associated with $\mathrm{Ni}$ sorption and desorption kinetics in soils. In this contribution, the effects of drinking water treatment residuals (DWTR) applications, as a low-cost adsorbent, on characteristics of $\mathrm{Ni}$ sorption /desorption kinetics in three arid soils having different properties were studied by batch experiments. Batch sorption kinetic experiments revealed that $\mathrm{Ni}$ sorption behavior involves fast and slow sorption reactions. The fast reaction accounted for $>70 \%$ of the total sorption within $15 \mathrm{~min}$ (the first sampling time). Desorption experiments revealed that $\mathrm{Ni}$ desorption was hysteretic in nature, which indicated a irreversible process. The time-sorption and desorption data generated for the DWTR treated and untreated soils fitted well to Elovich, power function and parabolic models as evidenced by high coefficient of determination $\left(R^{2}\right)$ and low standard error(SE). The rates of adsorptiondesorption in the soils studied were greatly influenced by the rate of DWTR added. Specifically, the rate of $\mathrm{Ni}$ sorption increased and the rate of released $\mathrm{Ni}$ decreased as the amount of DWTR added to the soils increased. The overall findings suggest that $\mathrm{Ni}$ retention capacity of soils can be increased via DWTR amendments to provide additional Al- based sorbents. Such information is critical for protecting natural resources, developing improved remediation strategies, and making better risk assessments.
\end{abstract}

Key words: Elovich and parabolic diffusion models, immobilization; remediation

\section{INTRODUCTION}

Nickel is a biotoxic heavy metal regarded as an important environmental pollutant in agricultural soils because of the potential adverse effects it may pose to food quality, soil health and the environment. Nickel may enter soil and aquatic environments via sewage sludge application, mine waste, industrial waste disposal, atmospheric deposition, and application of fertilizers and pesticides (Forstner, 1995). Understanding the kinetics and mechanisms of nickel sorption/desorption reactions is necessary to aid in the development of remediation strategies and the formulation of models designed to accurately predict potential bioavailability and mobility of contaminant metals (Liaghat, and Prasher, 2003; Samadi, 2006; Reyhanitabar etal., 2010).

Drinking Water Treatment Residuals (DWTR) is a by-product of water treatment facilities that use aluminium salts as coagulant. DWTR is derived from residual of treatment of raw water which contains mainly turbidity, colour, suspended clays and humic substances. It is the most widely generated waste worldwide, and is mostly landfilled at huge costs since it is regarded as a by -product of little known reuse value. DWTRs tend to have a mineral form similar to amorphous $\mathrm{Al}(\mathrm{OH})^{3}$ and act much like noncrystalline Al soil mineral species (Tisdale et al., 1985). Because of their amorphous nature, DWTRs have a large surface area (up to $105 \mathrm{~m}^{2} \mathrm{~g}^{-1}$ ) and, microporous structures, and an abundance of binding sites, (Makris et al., 2004). In recent years, more attention has focused on beneficial reuse of DWTR in land application (Elkhatib and Mahdy, 2008). Although the use of DWTR as soil amendment may seem viable, such an option cannot be considered without a detailed investigation on beneficial and detrimental effect on soil environmental quality. A literature search revealed little on the $\mathrm{Ni}$ sorptiondesotption and transport in DWTR-soil system. Such information is needed to quantify Ni mobility in the soil environment and would aid in evaluating the suitability of DWTR as a soil amendment for adsorbing Ni contaminant.

Therefore, in this study, our focus was investigating the sorption -desorption of $\mathrm{Ni}$ in soils having different properties and subsequent influence of DWTR application on Ni mobility in soils. Specifically, we carried out several batch experiments designed to quantify Ni interaction and mobility in soil as affected by application rates of DWTR. Accordingly, the objectives of this study were to (i) assess the capability of different kinetic models in describing the retention as well as the desorption behavior of $\mathrm{Ni}$ in different soil-DWTR systems and (ii) quantify the effects of DWTR amendments on the kinetics of Ni sorption and release in three arid soils having different physiochemical properties.

${ }^{1}$ Department of Soil and Water, College of Agriculture (Elshatby), Alexandria University, Alexandria, 21545, Egypt,

* Corresponding author: Elsayed A. Elkhatib, Alexandria University, College of Agriculture,

fax: 00203-5904684, e-mail: selkhatib1@yahoo.com

Received February 8, 2016, Accepted June 23, 2016 


\section{MATERIALS AND METHODS}

Soils and Drinking Water Treatment Residuals (DWTR)

Three different Egyptian soils were selected representing three different soil types of Egypt as Typic torrifluvent (Clay) from Kafr El-Dawar, Elbohera, Typic torripsamment (Sandy) from El-Bostan, Elbohera, and Typic calciorthids (Calcareous) from Borg Al-Arab, Alexandria. The experimental soils were collected from the top $15-\mathrm{cm}$ depth at several locations in the field and sub-samples of each soil type were airdried, ground and sieved ( $<2 \mathrm{~mm})$. The DWTRs were obtained from the drinking water treatment plant in Kafr El-Dawar, El-bohera, Egypt. The DWTRs were air-dried and sieved $(<2 \mathrm{~mm})$ prior to their use (Makris and Harris, 2005).

\section{Chemical and Physical Analyses}

The general physical and chemical properties of soils and DWTRs were determined (Table 1), including soil $\mathrm{pH}$ and electrical conductivity (EC) in the saturated paste extract (Richards, 1954), the $\mathrm{pH}$ and EC of DWTR s in 1: 2.5 suspension (Richards, 1954), calcium carbonate content by calcimeter (Nelson, 1982), particle size distribution by the hydrometer method (Day, 1965). The soil organic matter content (OM) was determined by the dichromate oxidation method (Nelson and Sommers, 1982). Soil cation exchange capacity (CEC) was determined by $1 \mathrm{M}$ NaOAC (Rhoades, 1982). Water holding capacity (WHC) was determined according to Skene et al. (1995). Concentrations of metals were determined according to the method described by Ure (1995). Ni was extracted with DTPA (Lindsay and Norvell, 1978) and determined by atomic absorption spectroscopy (AAS).

\section{Application Rates of DWTRs}

Application of DWTRs (at two rates: 10, and $50 \mathrm{~g}$ $\mathrm{kg}^{-1}$ soil w/w DW) was conducted to each soil type. These laboratory treatment levels are equivalent to the field application rates of 22 , and $110 \mathrm{Mg} \mathrm{ha}^{-1}$ for DWTRs, in a $15-\mathrm{cm}$ soil depth (with a bulk soil density of $1.50 \mathrm{~g} \mathrm{~cm}^{-3}$ ). The control has no additions of DWTRs. The treated soils were well mixed with DWTRs and transferred to a large plastic bin. Deionized water was added in the soil to bring the soil to its field capacity. Then, the treated and control soils were then transferred to polypropylene jars. The moisture content of the treated and control soils was kept constant during incubation by calculating the field capacity and periodically weighing the jars and adding de-ionized water to compensate for water loss via evaporation. Jars were covered with perforated plastic covers and incubated at $25^{\circ} \mathrm{C}$ for 60 days. After the incubation period, the soils were air-dried, crushed to pass a 2-mm sieve, and sub- samples were collected and used for the sorption-desorption experiments.

\section{Nickel Sorption Kinetics}

Kinetic retention using the batch method described by Amacher et al. (1988) was used to quantify $\mathrm{Ni}$ sorption by untreated and DWTR-treated soils (at rates of 0,10 and $50 \mathrm{gkg}^{-1}$ soil w/w DW) at $298 \pm 0.5 \mathrm{~K}$.

Table 1. Some physical and chemical characteristics of studied soils and drinking water treatment residuals (DWTR)

\begin{tabular}{lccccc}
\hline \multicolumn{1}{c}{ Characteristics } & Units & Clay $^{\dagger}$ & Sandy & Calcareous & DWTRs \\
\hline $\mathrm{pH}$ & & $8.13 \pm 0.05$ & $7.69 \pm 0.05$ & $8.08 \pm 0.06$ & $7.45 \pm 0.06$ \\
\hline $\mathrm{EC}$ & $\mathrm{dSm}^{-1}$ & $2.66 \pm 0.11$ & $3.84 \pm 0.12$ & $2.92 \pm 0.06$ & $1.67 \pm 0.04$ \\
\hline $\mathrm{CaCO}_{3}$ & $\mathrm{~g} \mathrm{~kg}^{-1}$ & $57.90 \pm 0.60$ & $2.40 \pm 0.30$ & $356.80 \pm 2.60$ & $\mathrm{nd}^{\S}$ \\
\hline Sand & $\mathrm{g} \mathrm{kg}^{-1}$ & $596.4 \pm 4.20$ & $868.2 \pm 5.10$ & $740.00 \pm 3.70$ & $\mathrm{nd}$ \\
\hline Silt & $\mathrm{g} \mathrm{kg}^{-1}$ & $141.3 \pm 1.50$ & $25.10 \pm 0.30$ & $101.50 \pm 1.90$ & $\mathrm{nd}$ \\
\hline Clay & $\mathrm{g} \mathrm{kg}^{-1}$ & $262.30 \pm 3.70$ & $106.70 \pm 2.20$ & $158.50 \pm 3.20$ & $\mathrm{nd}$ \\
\hline Texture & & $\mathrm{S} . \mathrm{C} . \mathrm{L}$ & $\mathrm{L} . \mathrm{S}$ & $\mathrm{S} . \mathrm{L}$ & $\mathrm{nd}$ \\
\hline $\mathrm{O}^{\dagger}$ & $\mathrm{g} \mathrm{kg}^{\dagger}$ & $8.50 \pm 0.15$ & $1.00 \pm 0.04$ & $4.60 \pm 0.15$ & $57.00 \pm 2.00$ \\
\hline KCl-Al & $\mathrm{mg} \mathrm{kg}^{-1}$ & $1.03 \pm 0.04$ & $0.13 \pm 0.02$ & $0.08 \pm 0.02$ & $28.18 \pm 1.03$ \\
\hline Olsen-P & $\mathrm{mg} \mathrm{kg}^{-1}$ & $24.75 \pm 0.25$ & $2.89 \pm 0.14$ & $18.70 \pm 0.80$ & $24.00 \pm 2.00$ \\
\hline CEC & ${\mathrm{Cmol}(+) \mathrm{kg}^{-1}}^{\dagger}$ & $39.13 \pm 0.98$ & $8.70 \pm 0.20$ & $26.00 \pm 2.02$ & $34.78 \pm 0.34$ \\
\hline Total Ni & $\mathrm{mg} \mathrm{kg}^{-1}$ & $25.01 \pm 0.02$ & $14.00 \pm 0.11$ & $17.02 \pm 0.03$ & $9.40 \pm 0.07$ \\
\hline DTPA-Extractable Ni & $\mathrm{mg} \mathrm{kg}^{-1}$ & $8.92 \pm 0.04$ & $5.13 \pm 0.05$ & $7.17 \pm 0.05$ & $2.49 \pm 0.07$ \\
\hline
\end{tabular}

${ }^{\dagger}$ Means of three samples \pm SD.

$\$$ O.M: organic matter; S.C.L: sandy clay loam, L.S: loamy sand, S.L: sandy loam

${ }^{\S}$ nd: not determined 
Triplicate 3-g samples of each soil and each time interval used were placed in Teflon centrifuge tubes and mixed with 30-mLsolution containing either $0,40,80$ or $160 \mathrm{mg} \mathrm{Ni} \mathrm{L^{-1 }}$ prepared in $0.05 \mathrm{M} \mathrm{CaCl}_{2}$ background solution. The mixtures were continuously shaken on a temperature-controlled shaker at120 rpm and then centrifuged at $5,000 \times \mathrm{g}$ for $10 \mathrm{~min}$ prior to sampling. Periodic 5-mL aliquots were removed at reaction times ranging from 15 to $1440 \mathrm{~min}$. (at equilibrium) and analyzed using AAS. Amount of $\mathrm{Ni}$ sorbed by the soil matrix was determined by the difference between the concentrations of the supernatant and that of the initial solutions. The sorption data were applied to three kinetic models: Elovich, power function and parabolic diffusion models.

\section{Desorption Kinetics}

Desorption or release experiments were conducted to assess the release of nickel as well as the extent of hysteresis behavior by the untreated and DWTRs treated soils. Sequential dilutions were initiated immediately after the last adsorption step for 40, 80 and $160 \mathrm{mg} \mathrm{Ni} \mathrm{L^{-1 }}$ initial concentrations of DWTR-soil mixture for the treatments of 0,10 and $50 \mathrm{~g}$ of DWTR $\mathrm{kg}^{-1}$ of soil. Each desorption step was carried out after equilibrium in adsorption was reached, by removing half of the supernatant after centrifugation, which was replaced by $15 \mathrm{~mL}$ of $0.005 \mathrm{M} \mathrm{Ca}\left(\mathrm{NO}_{3}\right)_{2}$ background solution and shaking for $48 \mathrm{~h}$. Six desorption steps were carried out. The fraction of nickel desorbed from each soil was calculated based on the change in concentration in solution (before and after desorption).

\section{Statistical Analysis}

The linear forms of different kinetic equations were applied to the adsorption and release data and their goodness of fit was evaluated based on the $R^{2}$, level of significance $(p)$, and standard error (SE). A relatively high $R^{2}$ value close or equal to 1 and low $\mathrm{SE}$ value indicate that the model successfully describes the kinetics of $\mathrm{Ni}^{+2}$ adsorption/desorption reactions.

\section{Theoretical Background Elovich Equation}

The Elvoich equation has been used to describe the kinetics of heterogeneous sorption and release reactions in soils (Chien and Clayton, 1980; Elkhatib and Hern, 1988).

The Elovich equation is:

$\mathrm{q}_{\mathrm{t}}=(1 / \beta) \ln (\alpha \beta)+(1 / \beta) \ln \mathrm{t}$

Where:

$\mathrm{q}_{\mathrm{t}}=$ the amount of $\mathrm{Ni}^{+2}$ adsorbed in time $\mathrm{t}$; $\alpha=$ the initial adsorption rate $\left(\mathrm{mg} \mathrm{g}^{-1} \mathrm{~min}^{-1}\right)$; and

$\beta=$ a constant related to the extent of surface coverage $\left(\mathrm{mg} \mathrm{g}^{-1}\right)$ and activation energy for chemisorptions

Thus a plot of $\mathrm{q}$ versus $\ln \mathrm{t}$ should give a linear relationship with the slope of $(1 / \beta)$ and intercept of $(1 / \beta) \ln (\alpha \beta)$.

\section{Parabolic Diffusion Equation (Laidler, 1965)}

This equation may be written:

$\mathbf{q}=\mathbf{a}+\mathbf{k}_{\mathrm{d}} \mathbf{t}^{\mathbf{1 / 2}}$

Where:

$\mathrm{q}=$ the amount of $\mathrm{Ni}$ sorbed (desorbed) in time $\mathrm{t}$

$\mathrm{a}=\mathrm{a}$ constant.

$\mathrm{k}_{\mathbf{d}}=$ apparent diffusion rate coefficient.

Thus, a plot of " $\mathrm{q} \mathrm{t}^{1 / 2}$ should provide a linear relationship if the reaction conforms to parabolic diffusion law.

\section{Power Function Equation}

The power function equation (Elkhatib et al., 1992) used in the form:

$\mathrm{q}=\mathrm{k}_{\mathrm{a}} \mathrm{C}_{\mathrm{o}} \mathrm{t}^{1 / \mathrm{m}}$

Where:

$\mathrm{q}=\operatorname{sorbed}($ desorbed $) \mathrm{Ni}^{+2}\left(\mathrm{mg} \mathrm{kg}^{-1}\right)$

$\mathrm{C}_{\mathbf{o}}=$ initial $\mathrm{Ni}^{+2}$ concentration $\left(\mathrm{mgl}^{-1}\right)$

$\mathrm{t}=$ reaction time $(\mathrm{min})$

$\mathrm{k}_{\mathrm{a}}=$ sorption (desorption) rate coefficient $\left(\mathrm{min}^{-1}\right)$, and $1 / \mathrm{m}=$ constant.

The parameter $\mathrm{k}_{\mathrm{a}} \mathrm{C}_{\mathbf{0}}$ and $1 / \mathrm{m}$ were calculated from the intercept and slope, respectively of the linear plots.

\section{RESULTS AND DISCUSSIONS}

\section{Sorption vs Time}

The Kinetics of Nickel adsorption on the three studied soils at 3 initial concentrations is illustrated in Figure (1). Within the first $15 \mathrm{~min}$, a very fast reaction occurred, accounting for $>70 \%$ of the total sorbed $\mathrm{Ni}$. This initial rapid reaction followed by a much slower rate that continued with all treatments for the durations of study period. The two sorption stages pattern has been reported as a characteristic of heavy metals sorption on clay and oxide surfaces (Eick et al., 2001; Voegelin et al. 2001; Jeon et al., 2003). Results from these studies suggest that the fast adsorption reaction is primarily due to the formation of bonds with functional groups that are readily present on the soil components (Jeon et al., 2003; Antoniadis and Tsadilas, 2007; Elkhatib et al,. 2007). 


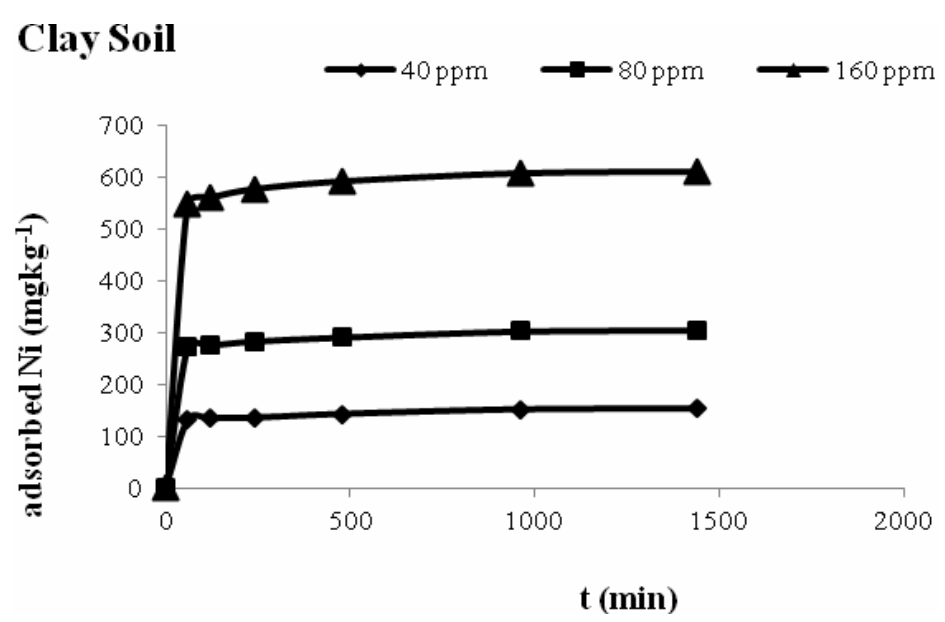

\section{Sandy Soil}

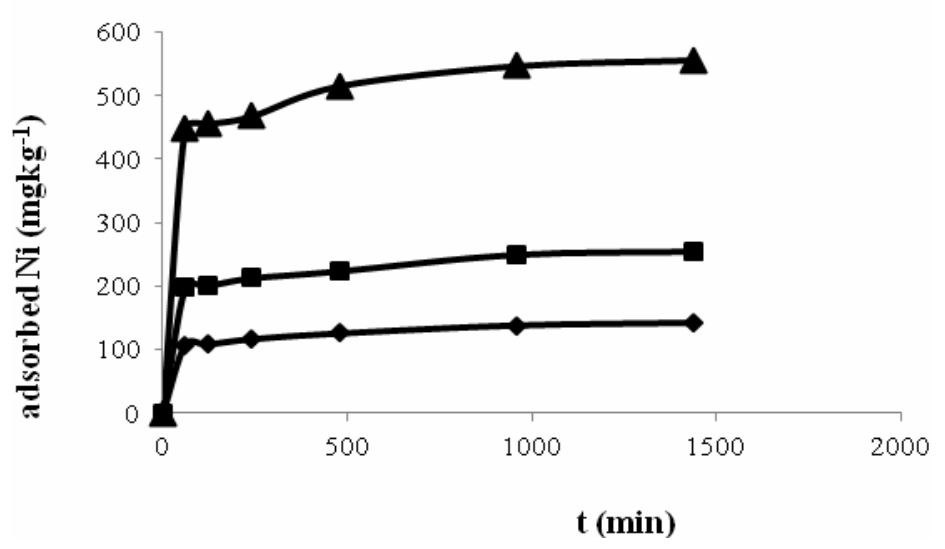

\section{Calcareous Soil}

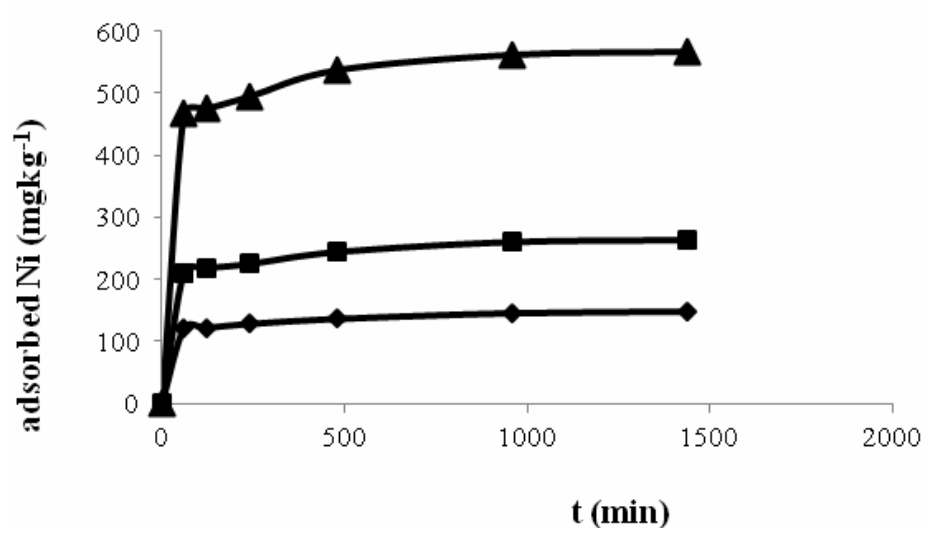

Figure 1. Kinetics of $\mathrm{Ni}^{+2}$ sorption on the three studied soils at $298 \mathrm{~K}$ and 3 different initial $\mathrm{Ni}^{+2}$ concentrations $\left(40,80\right.$, and $\left.160 \mathrm{mgl}^{-1}\right)$ 
Since soil is a mixture of organic and inorganic components, and it contains several different types of sorption sites, it is likely that several mechanisms are responsible for the slow sorption reactions. These may include diffusion, precipitation, and/or sorption reactions on sites that have a higher activation energy than the fast sorption sites (Voegelin et al., 2001; Loehr et al., 1996; Scheidegger et al., 1998).

When initial $\mathrm{Ni}^{+2}$ concentration was changed (40, $80,160 \mathrm{mg} / \mathrm{l})$ the extent of adsorption (\%) decreased with an increase in $\mathrm{Ni}$ concentration. However, the amount adsorbed per unit mass showed an increase with rise in initial $\mathrm{Ni}^{+2}$ concentrations (Figure 1). Sarvanane et al. 2002 and Gupta et al (2003) reported similar results with heavy metals sorption by montmorillonite and fly ash.

\section{Modeling Kinetics of Ni Adsorption}

Several mechanisms are suggested to contribute to the kinetics of heavy metal sorption on soils including (1) slow diffusion through intra-particle micropores (Strawn and Sparks, 1999); (2) heterogeneity of sorption sites ; sites having different affinities; (3) slow sorption due to the increase in surface charge upon the inner-sphere complexation of such ions (Jeon et al., 2003); (4) at neutral or basic condition, slow formation of new solid phases such as hydroxides or layered double hydroxides may cause kinetic effects and immobilization of nickel (Voegelin et al., 2001; Scheidegger et al., 1998; Businelli et al., 2004). Among the various sorption mechanisms mentioned above, the formation of surface-induced precipitates perhaps plays a significant role in the $\mathrm{Ni}$ sorption in neutral non-acidic soils. As the $\mathrm{pH}$ increases, $\mathrm{Ni}$ sorption was related to hydrolysis of divalent ions capable of forming innersphere complexes with clay lattice edges (Antoniadis and Tsadilas, 2007). Since most sorption processes is likely to take place by a multistep mechanism, several kinetic models were tested including the power function, Elovich, and the parabolic diffusion models.

Elovich Equation: The sorption data was fitted to Elovich equation which is of general application to chemisorption kinetics (Elkhatib etal, .1992, 2001; Loukidou et al., 2004). The Elovich plots of $\mathrm{Ni}^{+2}$ sorbed vs. ln of reaction time (q vs. lnt $\}$ for sandy, calcareous and clay soils as affected by different application rates of DWTR are shown in Figure 2. The coefficients of determination $\left(\mathrm{R}^{2}\right)$ from these plots values were significant at 0.01 levels(Tables 2\&4). Therefore, the Elovich model appeared to be successful in describing the kinetics of $\mathrm{Ni}^{+2}$ sorbed by the studied soils as well as DWTR amended soils.
Elovich parameters for the three soils as affected by DWTR applications at different initial Ni concentrations are given in Table (2). On increasing the initial Ni(II) concentration from 40 to $160 \mu \mathrm{gml}^{-1}$, the value of the initial adsorption rate (á) decreased from $0.137,0.084$ and 0.107 to $0.049,0.026$ and $0.028\left(\mathrm{mg} \mathrm{g}^{-1} \mathrm{~min}^{-1}\right)$ for DWTR unamended clay, sandy and calcareous soils respectively. In contrary, the Elovich equation $\hat{a}$ values for the unamended and DWTR amended soils increased with the increase in initial $\mathrm{Ni}^{+2}$ concentrations. With the increase in DWTR application rates, the adsorption rate (á) and the constant $\hat{a}$ increased showing that both the rate of chemisorption and the available adsorption surface for chemisorptions would increase. For example, in the case of clay soil, application of DWTR in a rate of $50 \mathrm{~g} \mathrm{~kg}^{-1}$ soil at $40 \mathrm{ugml}^{-1}$ initial concentration resulted in more than fourfold increases in the rate constants (Table 2). Such observations support the hypothesis that the addition of DWTR to soil alters the chemical properties of the soil system. We believe that the addition of DWTR adds extra adsorptive phases to soil systems and therefore alters its adsorptive characteristics.

The Parabolic Diffusion Model was also used to describe the kinetic data of $\mathrm{Ni}^{+2}$ sorption. Parabolic Diffusion plots for $\mathrm{Ni}^{+2}$ sorption by the 3 studied soils as affected by different DWTR application rates at $40 \mathrm{mgkg}^{-1} \mathrm{Ni}^{+2}$ initial concentration are shown in Figure 2. Linear relationships exist between $\mathrm{Ni}^{+2}$ sorbed and $\mathrm{t}_{1 / 2}$ for the three soils studied. Apparent diffusion rate coefficient $\left(\mathrm{k}_{\mathrm{id}}\right)$ is considered a measure of the relative rate of $\mathrm{Ni}^{+2}$, the $\mathrm{R}^{2}$ values ( 0.9 to 1.0$)$ led to the conclusion that the intraparticle diffusion process may play an important role as a rate determining step in the sorption reaction. Vadivelan and Kumar (2005), and Weng and Pan (2006) suggest that the adsorption process proceeds by surface adsorption followed by intraparticle diffusion. The apparent diffusion rate coefficients of the three soils as affected by DWTR application rates are shown in Table (2). Higher values of $\mathrm{k}_{\mathrm{id}}$ for DWTR-.soil systems illustrate an enhancement in the rate of adsorption, whereas larger " $k_{i d}$ " values illustrate an improved bonding between $\mathrm{Ni}^{+2}$ ions and the adsorbent particles. The " $k_{i d}$ " values followed the trend clay $>$ calcareous $>$ sandy soils. The higher values in the clay soil are attributed to its higher organic matter, clay content and cation exchange capacity compared to sandy and calcareous soils.

The effect of $\mathrm{Ni}^{+2}$ initial concentration on the diffusion rate coefficients were examined. When the initial concentrations of $\mathrm{Ni}^{+2}$ were increased, the observed sorption rates were faster for the higher 
concentration solutions (Table 2). The higher the initial $\mathrm{Ni}^{+2}$ concentration, the faster the adsorption rate. This observation is consistent with the assumed sorption mechanism whereby surface adsorption is predominant during the sorption process.

\section{Modeling Kinetics of Ni Desorption}

The linear forms of Elovich parabolic and power function kinetic models were tested and evaluated for their suitability to describe the Ni released from DWTR treated and untreated soils.

Table 2. Kinetics model parameters of $\mathrm{Ni}^{+2}$ sorption on the three studied soils at 3 initial $\mathrm{Ni}^{+2}$ concentration and different DWTR application rates.

\begin{tabular}{|c|c|c|c|c|c|c|c|c|c|}
\hline \multirow[b]{3}{*}{ DWTR } & \multicolumn{3}{|c|}{ Clay } & \multicolumn{3}{|c|}{ Sandy } & \multicolumn{3}{|c|}{ Calcareous } \\
\hline & \multicolumn{9}{|c|}{ Elovich model parameters } \\
\hline & $\alpha$ & $\beta$ & & $\alpha$ & $\beta$ & $\mathbf{R}^{2}$ & $\boldsymbol{\alpha}$ & $\boldsymbol{\beta}$ & $\mathbf{R}^{2}$ \\
\hline \multicolumn{10}{|c|}{$40{\mu \mathrm{gml}^{-1}}^{-1}$} \\
\hline 0 & 0.137 & $6.9 \times 10^{+06}$ & 0.94 & 0.084 & $1.1 \times 10^{+03}$ & 0.96 & 0.107 & $4.7 \times 10^{+04}$ & 0.96 \\
\hline 10 & 0.158 & $1.9 \times 10^{+08}$ & 0.95 & 0.087 & $2.8 \times 10^{+03}$ & 0.97 & 0.117 & $2.6 \times 10^{+05}$ & 0.95 \\
\hline 50 & 0.624 & $3.2 \times 10^{+39}$ & 0.89 & 0.161 & $1.3 \times 10^{+08}$ & 0.90 & 0.227 & $4.5 \times 10^{+12}$ & 0.92 \\
\hline \multicolumn{10}{|c|}{$80 \mu \mathrm{gml}^{-1}$} \\
\hline 0 & 0.090 & $6.8 \times 10^{+09}$ & 0.98 & 0.051 & $5.3 \times 10^{+03}$ & 0.95 & 0.056 & $3.2 \times 10^{+04}$ & 0.97 \\
\hline 10 & 0.095 & $3.5 \times 10^{+10}$ & 0.95 & 0.051 & $8.8 \times 10^{+03}$ & 0.95 & 0.062 & $2.0 \times 10^{+05}$ & 0.98 \\
\hline 50 & 0.168 & $1.9 \times 10^{+20}$ & 0.95 & 0.088 & $2.9 \times 10^{+09}$ & 0.93 & 0.125 & $3.7 \times 10^{+14}$ & 0.99 \\
\hline \multicolumn{10}{|c|}{$160 \mu \mathrm{gml}^{-1}$} \\
\hline 0 & 0.049 & $1.3 \times 10^{+11}$ & 0.99 & 0.026 & $6.3 \times 10^{+04}$ & 0.94 & 0.028 & $2.6 \times 10^{+05}$ & 0.96 \\
\hline 10 & 0.049 & $2.1 \times 10^{+11}$ & 0.99 & 0.028 & $1.6 \times 10^{+05}$ & 0.97 & 0.029 & $5.0 \times 10^{+05}$ & 0.98 \\
\hline 50 & 0.077 & $1.1 \times 10^{+19}$ & 0.95 & 0.066 & $8.5 \times 10^{+15}$ & 0.99 & 0.067 & $1.5 \times 10^{+16}$ & 0.99 \\
\hline \multicolumn{10}{|c|}{ Parabolic Diffusion model parameters } \\
\hline & $\mathbf{K}_{\text {id }}$ & $\mathbf{a}$ & $\mathbf{R}^{2}$ & $\mathbf{K}_{\mathrm{id}}$ & $\mathbf{a}$ & $\mathbf{R}^{2}$ & $\mathbf{K}_{\mathrm{id}}$ & $\mathbf{a}$ & $\mathbf{R}^{2}$ \\
\hline \multicolumn{10}{|c|}{$40 \mu \mathrm{gml}^{-1}$} \\
\hline 0 & 126.24 & 0.77 & 0.97 & 96.71 & 1.25 & 0.98 & 113.52 & 0.98 & 0.98 \\
\hline 10 & 131.65 & 0.66 & 0.97 & 103.98 & 1.20 & 0.98 & 118.59 & 0.90 & 0.98 \\
\hline 50 & 150.69 & 0.17 & 0.99 & 126.83 & 0.67 & 0.97 & 137.49 & 0.47 & 0.98 \\
\hline \multicolumn{10}{|c|}{$80 \mu \mathrm{gml}^{-1}$} \\
\hline 0 & 264.69 & 1.15 & 0.97 & 180.05 & 2.07 & 0.98 & 198.21 & 1.85 & 0.97 \\
\hline 10 & 267.49 & 1.11 & 0.99 & 188.29 & 2.06 & 0.99 & 211.30 & 1.68 & 0.98 \\
\hline 50 & 288.40 & 0.62 & 0.97 & 261.29 & 1.20 & 0.95 & 282.38 & 0.80 & 0.90 \\
\hline \multicolumn{10}{|c|}{$160 \mu \mathrm{gml}^{-1}$} \\
\hline 0 & 538.59 & 2.07 & 0.94 & 415.77 & 3.96 & 0.96 & 442.10 & 3.63 & 0.94 \\
\hline 10 & 538.11 & 2.23 & 0.97 & 428.11 & 3.74 & 0.99 & 449.42 & 3.49 & 0.96 \\
\hline 50 & 580.38 & 1.33 & 0.94 & 566.17 & 1.53 & 0.95 & 569.36 & 1.51 & 0.95 \\
\hline \multicolumn{10}{|c|}{ Power Function Model Parameters } \\
\hline & $1 / \mathrm{m}$ & $\mathbf{k}_{\mathrm{a}}$ & $\mathbf{R}^{2}$ & $1 / m$ & $\mathbf{k}_{\mathrm{a}}$ & $\mathbf{R}^{2}$ & $1 / \mathrm{m}$ & $\mathbf{k}_{\mathrm{a}}$ & $\mathbf{R}^{2}$ \\
\hline \multicolumn{10}{|c|}{$40 \mu \mathrm{gml}^{-1}$} \\
\hline 0 & 0.051 & 2.02 & 0.94 & 0.070 & 1.95 & 0.96 & 0.097 & 1.84 & 0.97 \\
\hline 10 & 0.043 & 2.05 & 0.95 & 0.089 & 1.89 & 0.98 & 0.062 & 1.98 & 0.96 \\
\hline 50 & 0.010 & 2.16 & 0.89 & 0.044 & 2.04 & 0.91 & 0.030 & 2.09 & 0.93 \\
\hline \multicolumn{10}{|c|}{$80 \mu \mathrm{gml}^{-1}$} \\
\hline 0 & 0.039 & 2.36 & 0.98 & 0.088 & 2.13 & 0.96 & 0.075 & 2.18 & 0.97 \\
\hline 10 & 0.036 & 2.37 & 0.95 & 0.084 & 2.15 & 0.96 & 0.066 & 2.22 & 0.99 \\
\hline 50 & 0.020 & 2.43 & 0.95 & 0.040 & 2.36 & 0.94 & 0.027 & 2.41 & 0.99 \\
\hline \multicolumn{10}{|c|}{$160 \mu \mathrm{gml}^{-1}$} \\
\hline 0 & 0.036 & 2.68 & 0.99 & 0.076 & 2.51 & 0.95 & 0.068 & 2.54 & 0.96 \\
\hline 10 & 0.037 & 2.67 & 0.98 & 0.070 & 2.53 & 0.97 & 0.065 & 2.55 & 0.98 \\
\hline 50 & 0.021 & 2.73 & 0.95 & 0.025 & 2.71 & 0.99 & 0.025 & 2.72 & 0.99 \\
\hline
\end{tabular}


Power function

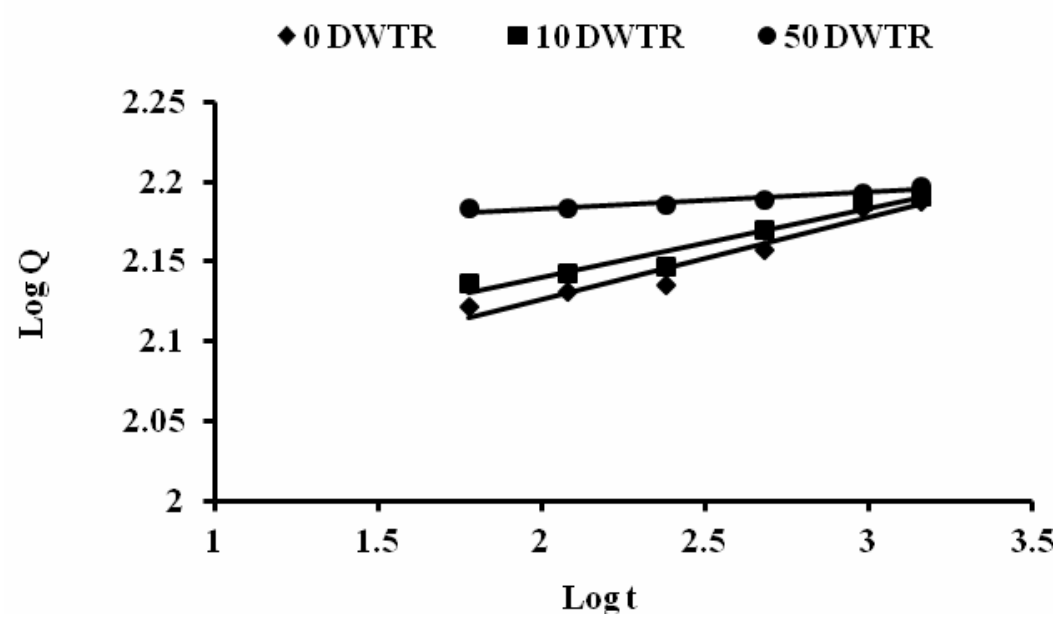

Elovich

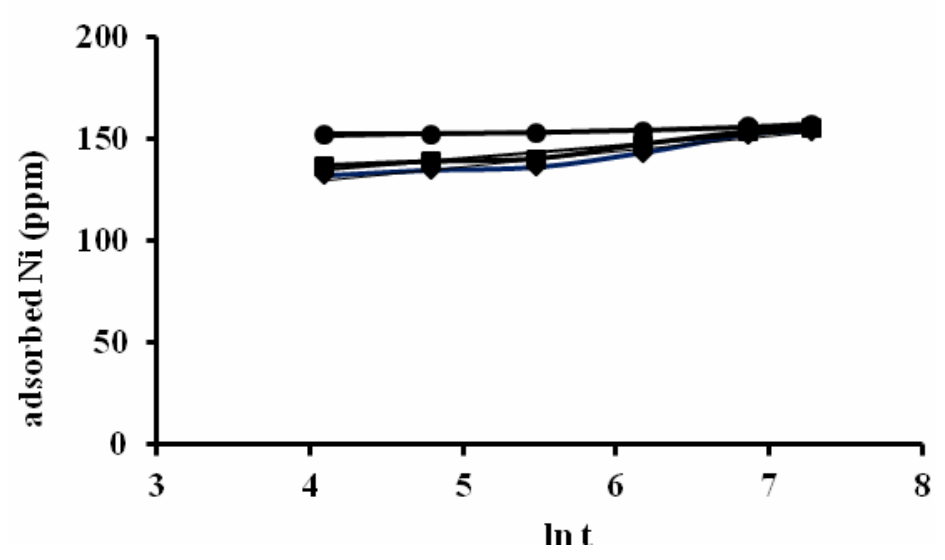

Parabolic diffusion

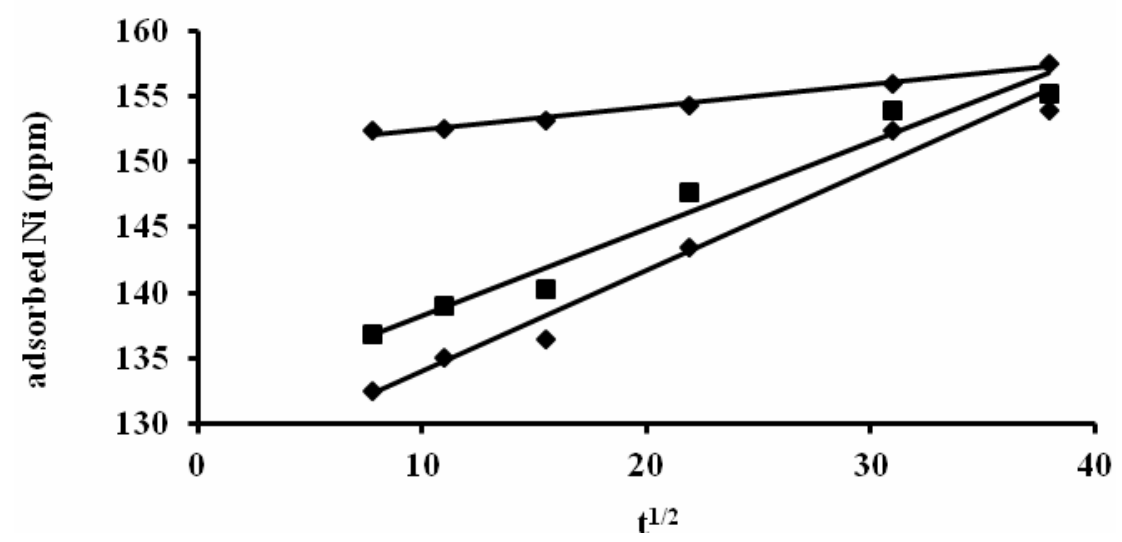

Figure 2. Power function,Elovich and parabolic diffusion model plots for Ni sorption in clay soils as affected by 10 and $50 \mathrm{~g} \mathrm{~kg}^{-1}$ DWTR at $40 \mathrm{mgl}^{-1}$ initial concentration 
Elovich Equation: The empirical Elovich equation was used to describe the $\mathrm{Ni}$ desorption rate. Elovich equation plots of $\mathrm{Ni}$ desorbed vs. In of reaction time at $298 \mathrm{~K}$ for clay, calcareous and sandy soils as affected by DWTR rates are shown in Figure (3). In all cases $\mathrm{R}^{2}$ values were significant at 0.01 levels(Table $3 \& 4)$. Therefore, the Elovich model appeared to be successful in describing the kinetics of $\mathrm{Ni}$ desorption from the studied soils as affected by two DWTR rates.

Parameters for the three soils and DWTR rates are shown in Table (3). The " $\alpha$ " values for clay, calcareous and sandy soils were high at different DWTR rates. In Elovich equations, " $\alpha$ " values are considered to be inversely proportional to ambient rate of desorption ((Laidler, 1965).

Parabolic Diffusion Model: The Parabolic Diffusion model was also used to describe the kinetic data of Ni release. Parabolic Diffusion plots for $\mathrm{Ni}$ released from the soils as affected by two DWTR rates are shown in Figure (3). Values of $\mathrm{R}^{2}$ relating $\mathrm{Ni}$ released to square root of reaction times were significant at 0.01 levels in most cases and they are given in Table 3.Therefore, the parabolic diffusion law was also successful in describing the kinetics of $\mathrm{Ni}$ released from the three studied soils as affected by the two DWTR application rates.

Parabolic Diffusion law parameters of the three soils as affected by DWTR rates are shown in Table (3). The apparent $\mathrm{Ni}$ diffusion rate coefficient $" \mathrm{k}_{\mathrm{d}}$ " in the parabolic diffusion law is considered a measure of the relative rate of $\mathrm{Ni}$ release. The $" k_{d}{ }^{\prime}$ values were higher in the sandy soil than the values in the calcareous and clay soil. The $" \mathrm{k}_{\mathrm{d}}$ " values followed the trend sandy $>$ calcareous $>$ clay at all studied DWTR rates. The lower values in the clay soil are attributed to its higher organic matter, clay content and cation exchange capacity. The " $\mathrm{k}_{\mathrm{d}}$ " values were lower in the presence of DWTR in the studied soils than the corresponding values in the absence of DWTR.

Power Function Model: The power function model was used to describe the Ni desorption data. The power function model plots of log Ni released vs. log of reaction time for the clay, sandy and calcareous soils at $298 \mathrm{~K}$ as affected by the two DWTR are shown in Figure (3). The power function model was successful in describing the kinetics of $\mathrm{Ni}$ release from the studied soils as evidenced by the significance of R2 values(Tables 3\& 4).

The modified Freundlich equation parameters are presented in Table 3.In general, the desorption rate coefficient $" k_{\mathbf{d}}$ " values of the DWTR amended soils were the lowest in comparison with control treatment.
Such observation indicates that $\mathrm{Ni}$ desorption rate decreased as a result of DWTR additions. At $160 \mathrm{ugg}^{-1}$ $\mathrm{Ni}$ initial concentration, the $" \mathrm{k}_{\mathbf{d}}$ " values of the sandy soil was $30.74,14.69$ and $4.47 \mathrm{~min}^{-1}$ at DWTR application rate of 0,10 and $50 \mathrm{~g} \mathrm{~kg}^{-1}$, respectively. The same observation was found in both clay and calcareous soils. However, the rate of Ni released in sandy soil was high as compared with calcareous and clay soils due to its low organic matter and clay contents (Table1).

\section{Comparison of Kinetic Equations to Describe Ni Sorption and Release in DWTR Amended Soils}

The integrated Elovich and power function and parabolic models described the sorption and desorption data of Ni in soils and DWTR-soil systems equally well as the $\mathrm{R}^{2}$ values were quite high and SE values were low (Table 4). At the very best, these results may indicate that intraparticle diffusion play an important role in $\mathrm{Ni}$ sorption in DWTR-treated and untreated soils. Eick et al. (2001) reported the suitability of parabolic diffusion law for explaining the Ni-sorption. Moreover, in such a complex sorption process, it is often possible that several equations differing in structure may give generally good descriptions of the data. This is because all the equations may account for some factors involved in the sorption process or some changes taking place during it, e.g. (1) energy of sorption sites are not uniform. (2) An increase in the numbers of vacant sites as sorption progress (3) Changes in solution conditions such as ionic strength that are known to influence the process. This would explain the observation that a set of data can often be described with comparable success by more than one equation.

The observations that substantial proportion of $\mathrm{Ni}$ sorbed by DWTR mended soils cannot be readily desorbed indicate that not only Ni sorption but also $\mathrm{Ni}$ desorption characteristics of DWTR-Soil systems are different from the control soils. The fast adsorption reactions and the slow desorption reactions observed in DWTR' soil systems (Tables 2 \&3) provide clear evidences for strong retention and immobilization of $\mathrm{Ni}$ in DWTR-soil system and imply that the $\mathrm{Ni}$ is irreversibly bound to DWTR-soil system. Sorption followed by diffusion of adsorbed ions within the solid oxide material has been proposed as a possible reason for decreased metal desorption with time ( Barrow et al., 1989). Therefore, it is reasonable to assume that $\mathrm{Ni}$ associated with oxides in DWTR-amended soils may be more difficult to desorb compared with the added sorbed $\mathrm{Ni}$ in the control soils. 
Table 3. Kinetics model parameters of $\mathrm{Ni}^{+2}$ Desorption on the three studied soils at $298 \mathrm{~K}, 3$ initial $\mathrm{Ni}^{+2}$ concentration and different DWTR application rates

\begin{tabular}{|c|c|c|c|c|c|c|c|c|c|}
\hline \multirow{3}{*}{ DWTR } & \multicolumn{3}{|c|}{ Clay } & \multicolumn{3}{|c|}{ Sandy } & \multicolumn{3}{|c|}{ Calcareous } \\
\hline & \multirow[b]{2}{*}{$\alpha$} & & & \multicolumn{3}{|c|}{ lovich model parameters } & \multirow[b]{2}{*}{$\alpha$} & \multirow[b]{2}{*}{$\beta$} & \multirow[b]{2}{*}{$\overline{\mathbf{R}^{2}}$} \\
\hline & & $\beta$ & $\mathbf{R}^{2}$ & $\alpha$ & $\boldsymbol{\beta}$ & $\mathbf{R}^{2}$ & & & \\
\hline \multicolumn{10}{|c|}{$40 \mathrm{\mu gml}^{-1}$} \\
\hline 0 & 0.17 & 0.26 & 0.96 & 0.07 & 0.49 & 0.96 & 0.09 & 0.35 & 0.98 \\
\hline 10 & 0.2 & 0.13 & 0.94 & 0.07 & 0.42 & 0.98 & 0.1 & 0.19 & 0.97 \\
\hline 50 & 0.46 & 0.06 & 0.99 & 0.11 & 0.27 & 0.98 & 0.12 & 0.16 & 0.95 \\
\hline \multicolumn{10}{|c|}{$80 \mu \mathrm{gml}^{-1}$} \\
\hline 0 & 0.07 & 0.4 & 0.98 & 0.04 & 2.26 & 0.99 & 0.06 & 0.62 & 0.99 \\
\hline 10 & 0.1 & 0.22 & 0.96 & 0.05 & 1.34 & 0.98 & 0.07 & 0.4 & 0.98 \\
\hline 50 & 0.3 & 0.1 & 0.98 & 0.08 & 0.58 & 0.99 & 0.09 & 0.25 & 0.95 \\
\hline \multicolumn{10}{|c|}{$160 \mu \mathrm{gml}^{-1}$} \\
\hline 0 & 0.05 & 1.27 & 1.00 & 0.02 & 6.29 & 0.98 & 0.04 & 1.83 & 0.97 \\
\hline 10 & 0.05 & 0.57 & 0.99 & 0.04 & 2.79 & 1.00 & 0.04 & 1.27 & 0.98 \\
\hline 50 & 0.12 & 0.18 & 0.97 & 0.04 & 1.27 & 0.99 & 0.06 & 0.49 & 0.99 \\
\hline \multicolumn{10}{|c|}{ Parabolic Diffusion model parameters } \\
\hline & $\mathbf{a}$ & $\mathbf{K}_{\mathrm{id}}$ & $\mathbf{R}^{2}$ & $\mathbf{a}$ & $\mathbf{K}_{\mathrm{id}}$ & $\mathbf{R}^{2}$ & $\mathbf{a}$ & $\mathbf{K}_{\mathrm{id}}$ & $\mathbf{R}^{2}$ \\
\hline \multicolumn{10}{|c|}{$40 \mathrm{mgml}^{-1}$} \\
\hline 0 & 2.80 & 0.60 & 0.97 & 2.78 & 1.52 & 0.99 & 2.16 & 1.12 & 0.95 \\
\hline 10 & -0.26 & 0.52 & 0.96 & 1.97 & 1.42 & 0.96 & -3.81 & 1.07 & 0.98 \\
\hline 50 & 0.18 & 0.22 & 0.96 & -1.4 & 1.11 & 0.99 & -3.18 & 0.91 & 0.97 \\
\hline \multicolumn{10}{|c|}{$80 \mu \mathrm{gml}^{-1}$} \\
\hline 0 & 0.41 & 1.51 & 0.96 & 32.99 & 2.57 & 0.90 & 5.14 & 1.78 & 0.98 \\
\hline 10 & -1.75 & 1.02 & 0.97 & 19.58 & 1.93 & 0.92 & 0.002 & 1.57 & 0.97 \\
\hline 50 & 0.37 & 0.35 & 0.97 & 7.33 & 1.30 & 0.94 & -2.37 & 1.17 & 0.97 \\
\hline \multicolumn{10}{|c|}{$160 \mu \mathrm{gml}^{-1}$} \\
\hline 0 & 17.84 & 2.23 & 0.95 & 76.81 & 4.27 & 0.90 & 26.92 & 2.79 & 0.93 \\
\hline 10 & 2.15 & 2.02 & 0.96 & 37.98 & 2.70 & 0.94 & 17.83 & 2.35 & 0.93 \\
\hline 50 & -2.25 & 0.89 & 0.96 & 14.62 & 2.30 & 0.92 & 0.70 & 1.84 & 0.96 \\
\hline \multicolumn{10}{|c|}{ Power Function Model Parameters } \\
\hline & $1 / \mathbf{m}$ & $\mathbf{k}_{\mathrm{d}}$ & $\mathbf{R}^{2}$ & $1 / \mathbf{m}$ & $\mathbf{k}_{\mathrm{d}}$ & $\mathbf{R}^{2}$ & $1 / \mathbf{m}$ & $\mathbf{k}_{\mathrm{d}}$ & $\mathbf{R}^{2}$ \\
\hline \multicolumn{10}{|c|}{$40 \mu \mathrm{gml}^{-1}$} \\
\hline 0 & 0.41 & 1.31 & 0.98 & 0.46 & 2.15 & 1.00 & 0.51 & 5.76 & 0.97 \\
\hline 10 & 0.55 & 0.38 & 0.97 & 0.51 & 1.39 & 0.97 & 0.69 & 0.26 & 0.98 \\
\hline 50 & 0.55 & 0.17 & 0.96 & 0.51 & 0.91 & 0.98 & 0.67 & 0.25 & 0.98 \\
\hline \multicolumn{10}{|c|}{$80 \mathrm{mgml}^{-1}$} \\
\hline 0 & 0.56 & 1.05 & 0.97 & 0.34 & 11.36 & 0.95 & 0.46 & 2.56 & 0.99 \\
\hline 10 & 0.59 & 1.88 & 0.98 & 0.36 & 7.01 & 0.97 & 0.55 & 1.13 & 0.98 \\
\hline 50 & 0.51 & 0.34 & 0.99 & 0.43 & 2.63 & 0.97 & 0.60 & 0.56 & 0.97 \\
\hline \multicolumn{10}{|c|}{$160 \mu \mathrm{gml}^{-1}$} \\
\hline 0 & 0.38 & 6.41 & 0.98 & 0.28 & 30.74 & 0.96 & 0.37 & 9.28 & 0.96 \\
\hline 10 & 0.54 & 1.69 & 0.97 & 0.31 & 14.69 & 0.97 & 0.40 & 6.19 & 0.97 \\
\hline 50 & 0.66 & 0.28 & 0.97 & 0.44 & 4.47 & 0.94 & 0.54 & 1.44 & 0.98 \\
\hline
\end{tabular}




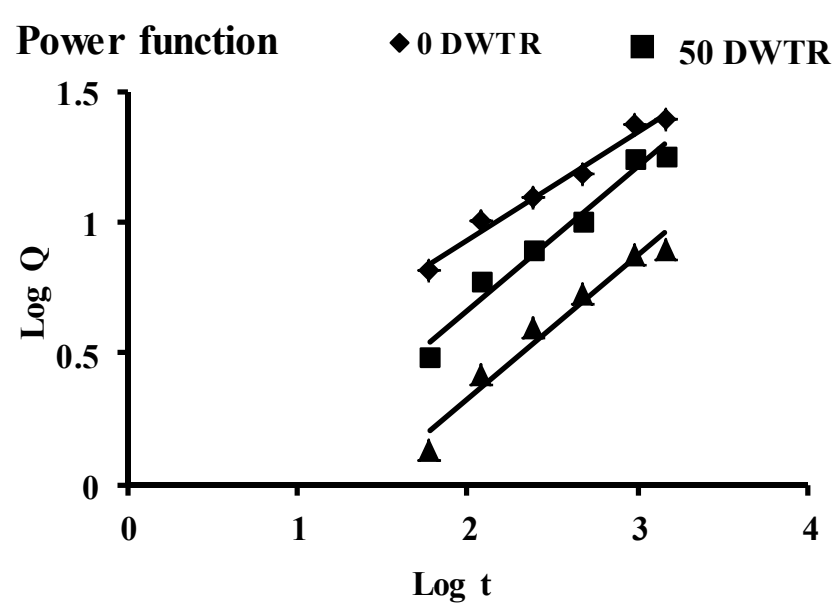

Elovich

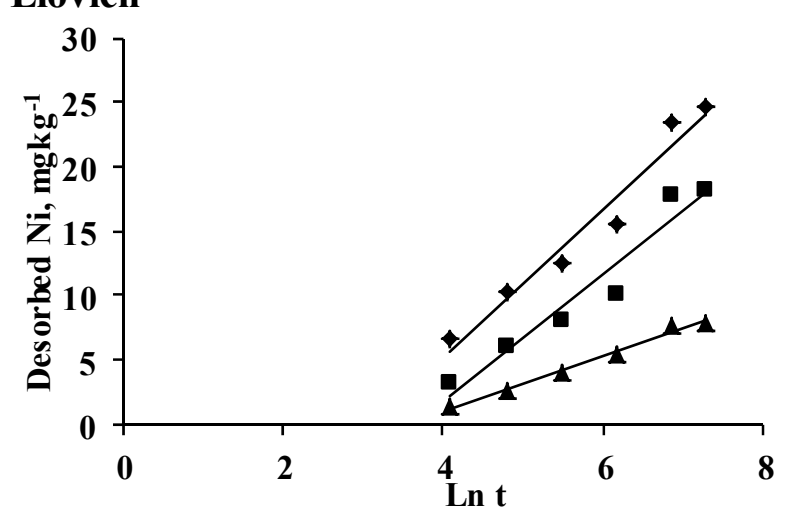

Parabolic

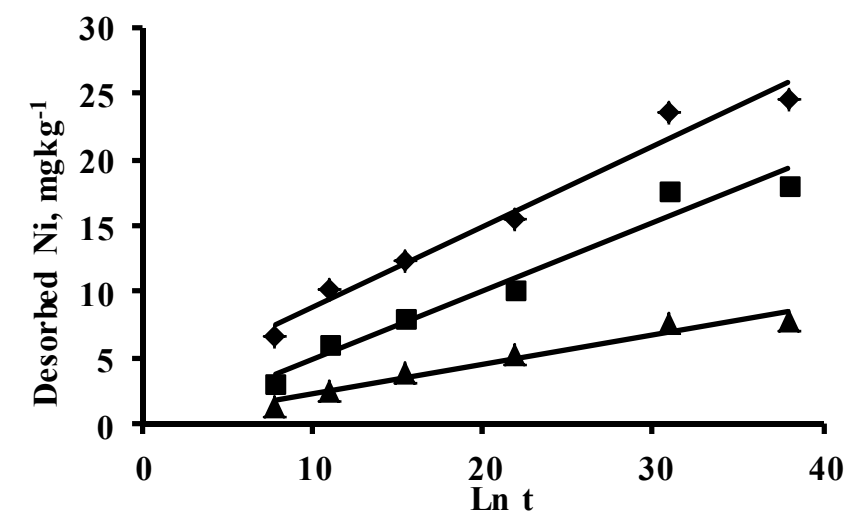

Figure 3. Power function,Elovich and parabolic diffusion model plots for Ni desorption in clay soils as affected by 10 and $50 \mathrm{~g} \mathrm{~kg}^{-1}$ DWTR at $40 \mathrm{mgl}^{-1}$ initial concentration 
Table 4. Range and mean values of coefficient of determination $\left(R^{2}\right)$ and standard error of estimates (SE) for different models fitted to the nickel sorption and desorption kinetics on the three studied soils amended with/without drinking water treatment residuals (DWTR) at three initial nickel concentrations

\begin{tabular}{|c|c|c|c|c|c|c|}
\hline \multirow{3}{*}{ Model } & \multicolumn{3}{|c|}{$\mathbf{R}^{2}$} & \multicolumn{3}{|c|}{ SE } \\
\hline & \multicolumn{2}{|c|}{ Range } & \multirow{2}{*}{ Mean } & \multicolumn{2}{|c|}{ Range } & \multirow{2}{*}{ Mean } \\
\hline & Max & Min** & & Max & Min & \\
\hline \multicolumn{7}{|l|}{ Adsorption } \\
\hline Parabolic Diffusion & 0.99 & 0.90 & 0.97 & 4.38 & 0.09 & 1.51 \\
\hline Elovich & 0.99 & 0.89 & 0.96 & 1.22 & 0.03 & 0.22 \\
\hline Power function & 0.99 & 0.89 & 0.96 & 0.20 & 0.02 & 0.09 \\
\hline \multicolumn{7}{|l|}{ Desorption } \\
\hline Parabolic Diffusion & 0.99 & 0.90 & 94 & 0.90 & 0.14 & 0.48 \\
\hline Elovich & 1.00 & 0.94 & 94 & 0.32 & 0.07 & 0.29 \\
\hline Power function & 1.00 & 0.94 & 97 & 0.14 & 0.03 & 0.09 \\
\hline
\end{tabular}

** Significant at $\mathrm{p} \leq 0.001 \quad \mathrm{SE}=$ standard error of estimate

\section{CONCLUSION}

This research examined the influence DWTR on the sorption and desorption kinetics of $\mathrm{Ni}^{+2}$ on 3 different soils of arid region. Both the sorption and desorption kinetics were best described by integrated Elovich and power function and parabolic models. Nickel batch adsorption experiments revealed that Ni adsorption was higher onto the DWTR amended soils than the unamended soils as DWTR acted as an adsorbent in the DWTR-soil systems by increasing Ni retention capacity. The fast adsorption reactions and the slow desorption reactions observed in DWTR' soil systems provide clear evidences for strong retention and immobilization of Ni in DWTR-soil system and imply that the $\mathrm{Ni}$ is irreversibly bound to DWTR-soil system Such information is critical for protecting natural resources, developing improved remediation strategies, and making better risk assessments.

\section{ACKNOWLEDGEMENTS}

We gratefully acknowledge the financial support from the Egyptian Science and Technology Development Fund (STDF4977-2013).

\section{REFERENCES}

Amacher M.C.,H.M. Selim, and I.K.Iskandar.1988. Kinetics of Chromium(VI) and Cadmium Retention in Soils: A Nonlinear Multireaction Model. Soil Sci Soc.Am. J. 44:265-268

Antoniadis V., C.D.Tsadilas .2007. Sorption of Cadmium, Nickel and Zinc in Mono- and Multimetal Systems. App. Geoch. 22:2375-2380

Barrow N.J., J.Gerth, and G.W.Bruemmer. 1989. Reaction Kinetics of the Adsorption and Desorption of Nickel, Zinc and Cadmium by Geothite. II. Modelling the Extent and Rate of Reaction. J. Soil Sci. 40:437-450.
Businelli D., F.Casciari, and G.Gigliotti. 2004. Sorption Mechanisms Determining Ni (II) Retention by a Calcareous Soil. Soil Sci.169: 355-362.

Chien S. H. and W. R. Clayton.1980. Application of Elovich Equation to the Kinetics of Phosphate Release and Sorption in Soils. Soil Sci. Soc. Am. J., 44:265-268.

Day P.R. 1965. Particle fraction and particle size analysis. In Methods of Soil Analysis, Eds., Black, A.C., D.D. Evans, L.E. Ensminger, J.L. White, and F.E. Clark. Part I. American Society of Agronomy, Madison, Wisconsin, USA. pp: 545-566.

Eick M.J., B.R. Naprstek, and P.V.Brady. 2001. Kinetics of $\mathrm{Ni}(\mathrm{II})$ Sorption and Desorption on Kaolinite: Residence Time Effects. Soil Sci. 166:11-1

Forstner U. 1995. Land Contamination by Metals, Global Scope and Magnitude of Problem. In: Allen HE (ed) Metal speciation and contamination of soil, CRC Press, Boca Raton, FL pp. 1-34.

Elkhatib E.A. and J.L.Hern. 1988. Kinetics of Phosphorus Desorption from Appalachian Soils. Soil Sci.145: 11-19.

Elkhatib E.A., G.El-shebiny, and A.M.Balba.1992. Kinetics of lead sorption in calcareous soils. Arid Soil Res.Rehab. 6: 297-310.

Elkhatib E.A., A.G. Thabet and M.L.Mohram. 2001.Sorption of Cadmium in Surfactant-Amended Soils. Arid Land Res. Manag. 15:385-394.

Elkhatib E.A., A.M.Mahdy, M.E.Saleh, and N.H.Barakat. 2007. Kinetics of copper desorption from soils as affected by different organic ligands. Int.J. Environ. Sci. Tech. 4: 331-338..

Elkhatib, E.A. and A.M.Mahdy. 2008. Land application of Water Treatment Residuals: Effect on Wheat Yield and the Availability of Phosphorus and aluminium Int. J. Environ.Waste Manag.2: 647-665.

Gupta V.K., C.K.Jain, I. Ali, M.Sharma, and V.K.Saini. 2003. Removal of Cadmium and Nickel from Wastewater Using Bagasse Fly Ash - A Sugar Industry Waste. Water Res. 37: 4038-404. 
Jeon B., B.A.Dempsey, and W.D.Burgos. 2003. Sorption Kinetics of $\mathrm{Fe}(\mathrm{II}), \mathrm{Zn}(\mathrm{II}), \mathrm{Co}(\mathrm{II}), \mathrm{Ni}(\mathrm{II}), \mathrm{Cd}(\mathrm{II})$, and $\mathrm{Fe}(\mathrm{II}) / \mathrm{Me}(\mathrm{II})$ onto Hematite. Water Res. 37: 4135-4142.

Laidler K. J. 1965. Chemical Kinetics. $3^{\text {rd }}$ ed. McGraw-Hill, Inc., New York.

Liaghat, A. and S.O. Prasher. 2003.Application of Mathematical Modeling to Determine the Size of On-Site Grass Filters for Reducing Farm Pesticide Pollution. J.Agric. Sci. Technol., 5: 125-134.

Lindsay W.L. and W.A.Norvell. 1978. Development of DTPA Soil Test for Zinc, Iron, Manganese and Copper. Soil Sci. Soc. Am. J. 42: 421-428.

Loehr R.C.and M.T.Webste. 1996. Behavior of Fresh vs. Aged Chemicals in Soils. J. Soil Cont. 5:361-393.

Loukidou M.X., A.I.Zouboulis, T.D.Karapantsios, K.A.Matis. 2004. Equilibrium and Kinetic Modeling of Chromium (VI) Biosorption by Aeromonas Caviae. Colloids and Surfaces A: Physicochemical and Engineering 242: 93-104.

Makris K.C., W.G.Harris, G.A.O'connor, and T.A.Obreza.2004.Phosphorus Immobilization In Micropores of Drinking-Water Treatment Residuals: Implications for Long-Term Stability. Environ. Sci. Techn. 38:6590-6596.

Makris K.C. and W.G.Harris. 2005. Time Dependency and Irreversibility Of Water Desorption by Drinking Water Treatment Residuals: Implication for Sorption Mechanisms. J. Colloid Inter. Sci. 294: 151-154.

Nelson R.E.1982. Carbonate and gypsum. In A.L. Page, R.H. Miller and D.R. Keeney (editors) Methods of Soil Analysis. American society of Agronomy, Madison, WI. pp. 181-197

Nelson D.W. and L.E.Sommers .1982. Total Carbon, Organic Carbon and Organic Matter. In A.L. Page (Edition) Methods of Soil Analysis. American society of Agronomy, Madison, WI. pp. 539-579.

Rhoades J. D. 1982. Cation Exchange Capacity. In A.L. page, Miller, R.H. and Keeney, D.R. (editors), Chemical and Microbiological, American society of Agronomy, Madison, WI. pp. 149-157.

Reyhanitabar A., M. Ardalan, , R. J. Gilkes, and G.Savaghebi.2010 Zinc Sorption Characteristics of Some Selected Calcareous Soils of Iran. J.Agric. Sci. Technol. 12: 99-110.
Richards L.A. 1954. Diagnosis and Improvement of Alkaline Soils. USDA Handbook 60. Washington, DC, USA: US Government Printing Office.

Samadi A. 2006. Phosphorus Sorption Characteristics in Relation to Soil Properties in Some Calcareous Soils of Western Azarbaijan Province. J.Agric. Sci. Technol., 8: 251-264.

Saravanane R., T.Sundaranjan, and S.S. Reddy. 2002. Efficiency of Chemically Modified Low Cost Adsorbents for the Removal of Heavy Metals from Wastewater: A Comparative Study. Ind. J. Environ. Health 44: 78-87.

Scheidegger A. M., D. G.Strawn, G. M . Lamble, and D. L. Sparks.1998.The kinetics of Mixed Ni-Al Hydroxide Formation on Clay and Aluminum Oxide Minerals: A Time-Resolved XAFS Study. Geochimica et Cosmochimica Acta 62: 2233-224

Skene T.M., M.Oades, and G. Kilmore. 1995.Water Treatment Sludge: A Potential Plant Growth Medium. Soil Use and Manag. 11: 29-33.

Strawn D.G. and D.L. Sparks.1999. The USE of XAFS to Distinguish Between Inner- and Outer-Sphere Lead Adsorption Complexes on Montmorillonite. J.Colloid Inter. Sci. 216: 257-269.

Tisdale S.L., W.L. Nelson, and J.D. Beaton.1985.Soil Fertility and Fertilizers. $4^{\text {th }}$ ed. Macmillan, New York.

Ure A.M. .1995. Methods of Soil Analysis for Heavy Metals in Soils. In B.J. Alloway (Editor), Heavy Metals in Soils, $2^{\text {nd }}$ ed, Blackie Academic and Professional, London.pp 58-95.

Vadivelan V. and K.V.Kumar . 2005.Equilibrium, Kinetics, Mechanism and Process Design for The Sorption of Methylene Blue onto Rice Husk. J.Colloid Inter. Sci. 286: $90-100$.

Voegelin, A.and R.Kretzschmar. 2005. Formation and Dissolution of Single and Mixed Zn and Ni Precipitates In Soil: Evidence From Column Experiments and Extended X-Ray Absorption Fine Structure Spectroscopy. Environ. Sci. Techno. 39: 5311-5318.

Weng, C. and Y.Pan.2006. Adsorption Characteristics of Methylene Blue from Aqueous Solution by Sludge Ash. Colloids and Surfaces A: Physicochemical and Engineering 274: $154-162$. 


\section{الملغص الهرب}

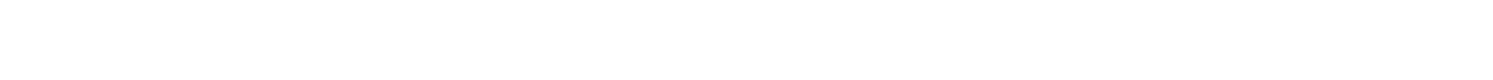

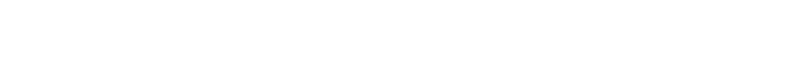

وأشارت نتائج تحرر النيكل أن الفاعل غير عكسي. وقم وصف نتائج حركية المتصاص وتحرر النيكل بنجاح

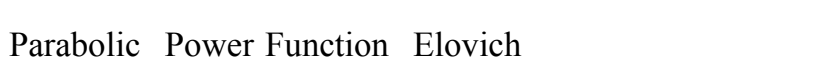

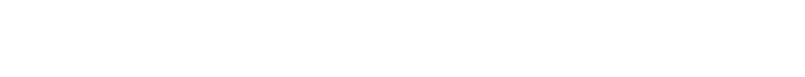

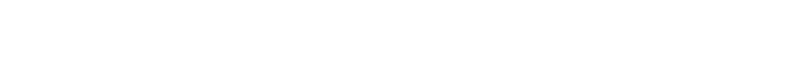
معل التحرر. وتشير نتائج الدرلمة أيضاً أن مخلفات تققية ميه اللثرب تعتبر مادة جية لمعالجة الأراضى الملوثة بالنيكل. الكلملت المفتلحية: النيكل - إمتصاص- تحرر- حركية.
تعتمد حركية وصلاحية النيكل ف في الأراض ي علا ي

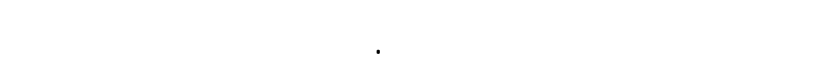

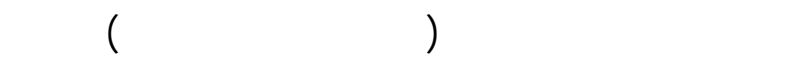

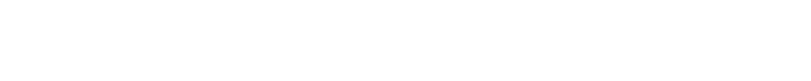
المنلطق الجلفة في تجربة معملية.

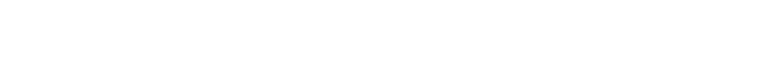

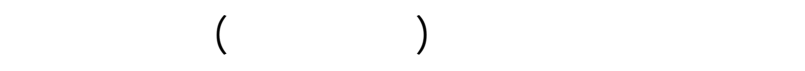

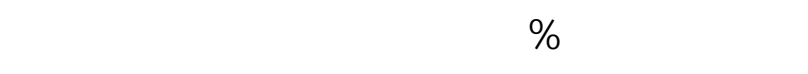
دقيقة. 